JAN 171968

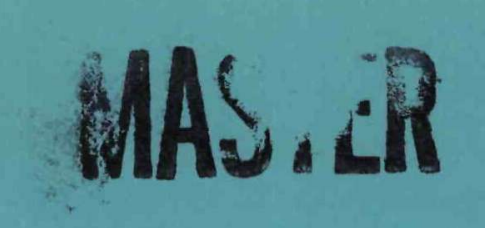

NAA-SR-Memo-12582

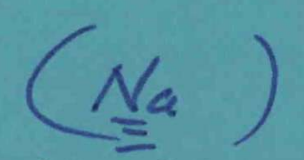

\title{
Liquid Metal Level Measurement (Sodium)
}

State-of-the-Art Study

AEC Research and Development Report

Liquid Metal Engineering Center 
This report may not be published without the approval of the Patent Branch, AEC.

\section{LEGAL NOTICE}

This report was prepared as an account of Government sponsored work. Neither the United States, nor the Commission, nor any person octing on behalf of the Commission:

A. Makes any warranty or representation, express or implied, with respect to the accuracy, completeness, or usefulness of the information contained in this report, or that the use of any information, apparatus, method, or process disclosed in this report may not infringe privately owned rights; or

B. Assumes any liabilities with respect to the use of, or for damages resulting from the use of information, apparatus, method, or process disclosed in this report.

As used in the above, "person acting on behalf of the Commission" includes any employee or contractor of the Commission, or employee of such contractor, to the extent that such employee or contractor of the Commission, or employee of such contractor prepares, disseminates, or provides access to, any information pursuant to his employment or contract with the Commission, or his employment with such contractor. 


\section{DISCLAIMER}

This report was prepared as an account of work sponsored by an agency of the United States Government. Neither the United States Government nor any agency Thereof, nor any of their employees, makes any warranty, express or implied, or assumes any legal liability or responsibility for the accuracy, completeness, or usefulness of any information, apparatus, product, or process disclosed, or represents that its use would not infringe privately owned rights. Reference herein to any specific commercial product, process, or service by trade name, trademark, manufacturer, or otherwise does not necessarily constitute or imply its endorsement, recommendation, or favoring by the United States Government or any agency thereof. The views and opinions of authors expressed herein do not necessarily state or reflect those of the United States Government or any agency thereof. 


\section{DISCLAIMER}

Portions of this document may be illegible in electronic image products. Images are produced from the best available original document. 


\section{Liquid Metal Level Measurement (Sodium) State-of-the-Art-Study}

By

H.W. Slocomb

\section{LEG A L NOTICE}

This report was prepared as an account of Government sponsored work. Neither the United
States, nor the Commission, nor any person acting on A. Makes any warranty or representation, expressed or of the Commission.

racy, completeness, or usefulness of the information con implied, with respect to the accuof any information, apparatus, method, information contained in this report, or that the use privately awned rights; or

use of any information, apparatus, method, to the use of, or for damages resulting from the As used in the above, "person acting on behalf of the Com in this report.

ployee or contractor of the Commission, or employe the Commission" includes any emdich employee or contractor of the Commussion of such contractor, to the extent that dissemnates, or provides access to, any information puyee of such contractor prepares with the Commission, or his employment with swath pursuant to his employment or contract

\section{Liquid Metal Engineering Center}

Operated for

the U.S. Atomic Energy Commission by Atomics International

A Division of North American Rockwell Corporation

Contract: AT(04-3)-700

Issued: November 15, 1967 
-

(⿸丆口

1 


\section{CONTENTS}

Page

I. Introduction $\ldots \ldots \ldots \ldots \ldots$

II. Electrical Contact Probes (Point Contact) . . . . . . . . . 6

III. Resistance Probes. . . . . . . . . . . . . . . . . . 7

IV. Inductive Probes ....................... 11

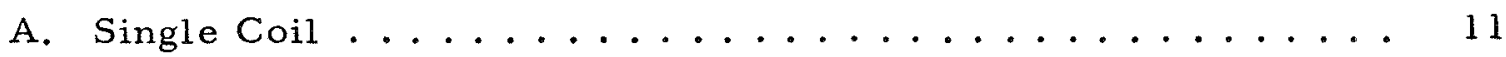

B. Multicoil, Temperature Compensated ............. 11

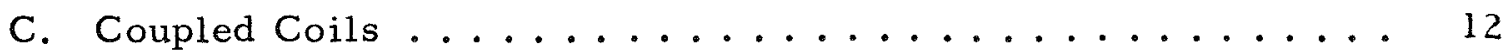

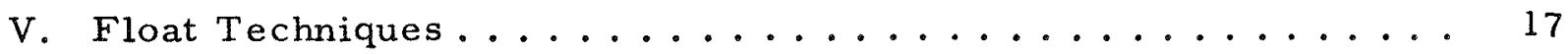

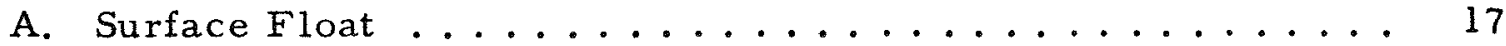

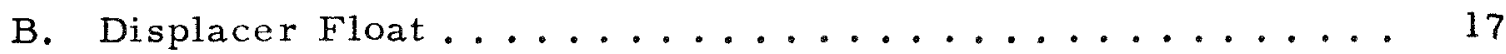

VI. Pressure Transducers ......................... 19

VII. Other Devices and Techniques ................. 20

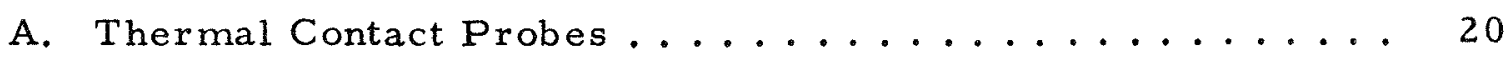

B. Electrical Capacitance Probes ............... 20

C. Gamma Ray Absorption Technique ............. 20

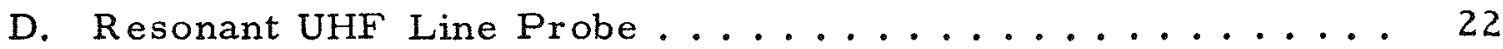

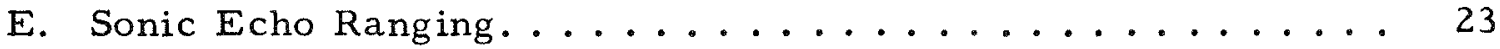

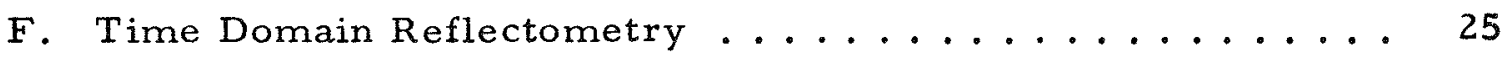

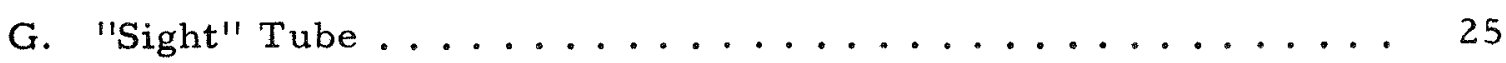

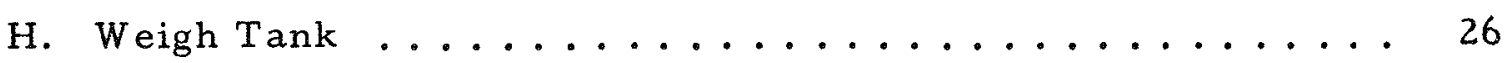

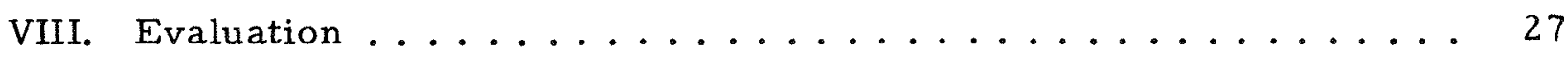

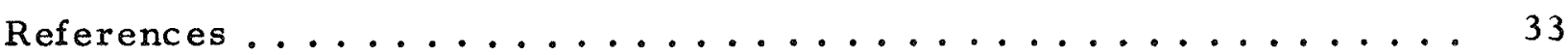

TABLES

1. Summary of Liquid Metal Level Measurement Techniques . . . . . 3l

\section{FIGURES}

1. Insulated Contact Level Indicator . . . . . . . . . . . . . 6

2. High Resistance Contact Level Indicator . . . . . . . . . . . . 6

NAA -SR - MEMO- 12582 


\section{FIGURES}

3. Resistance Tube Level Gage Mounted in Bottom of Vessel. . . . . 8

4. Resistance Tube Level Gage Mounted in Top of Vessel . . . . . . . 8

5. Two-Wire "J" - Probe with Externally Connected Temperature

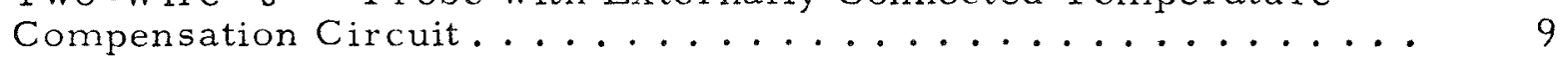

6. Simple Induction Level Gage Design ................ 10

7. Inductance Level Gage Using a Temperature Compensating

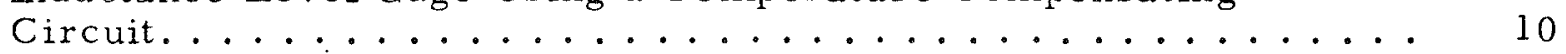

8. Level Gage Using Bifilar Coil . . . . . . . . . . . . . . . . . . 14

9. Level Gage Using Coils Inductively Coupled in Separate Thimble . . 14

10. Level Gage Using Coils Inductively Coupled by Liquid Metals . . . 15

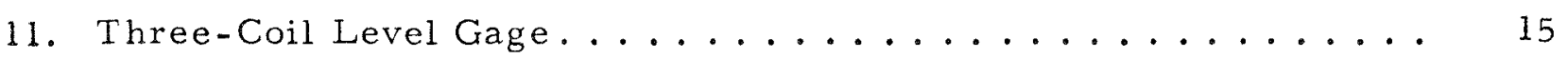

12. Float Type Level Indicators. . . . . . . . . . . . . . . 17

13. Differential Pressure Method of Measuring Level . . . . . . . . 19

14. Electrical Capacitance Level Gage . . . . . . . . . . . . . 21

15. Gamma Ray Level Indicator. . . . . . . . . . . . . . . . . 22

16. Resonant Transmission Line, Level Gage . . . . . . . . . . . 23

17. Echo Ranging Method of Level Measurement ............. 24

18. Ultrasonic Level Gage, Standing Wave Ratio Type.......... 24

19. "Sight Tube" Level Gage...................... 26 


\section{INTRODUCTION}

Several forms of liquid metal level measuring devices have been used in liquid metal systems. The most commonly used types to date are the point contact, the resistance tube, and various forms of inductive sensors. Pressure operated devices such as the differential pressure and bubbler techniques have had some use. Other techniques used or proposed include the surface float, displacement float, ultrasonic, pulse delay line, and mic rowave cavity.

The excellent electrical conductive property of liquid metal is used as the basis for point contact, resistance, and inductive types of level measuring probes. In one type of measurement, electrodes forming a part of an electric circuit are immersed into the liquid metal, and the electrical circuit resistance is varied by the direct contact with the liquid metal. In the inductive measurement technique the electrical current is induced into the liquid metal by a coil which eliminates the necessity for an electrical contact between the liquid metal and the level measuring circuitry.

Wetting is a critical factor in the use of an electrical circuit which depends upon electrode contact with the liquid metal. For all instrumentation applications, complete wetting is essential to avoid errors introduced by erratic contact resistance. At temperatures below approximately $800^{\circ} \mathrm{F}$ wetting is strongly affected by material surface condition. Above $800^{\circ} \mathrm{F}$ the factors which inhibit wetting are overcome and complete wetting is assured. The wetting problem is important when filling or operating liquid metal systems at lower temperatures and it is necessary to measure liquid levels with a degree of confidence.

The measurement techniques and their characteristics, including wetting, are discussed in the following pages.

NAA-SR - MEMO- 12582 


\section{ELECTRICAL CONTACT PROBES (POINT CONTACT)}

The simplest level gage (Figure 1) is an electrical circuit in which the liquid metal is one contact of a switch and the other contact is a rod projecting through an insulating bushing. The liquid metal contacting the rod closes the switch, thus forming an indication of the liquid level at that point. A group of rods of various lengths can be used to indicate the liquid metal level over a range of discrete point valves.

A disadvantage is that condensation of liquid metal vapors on the insulating bushing, and poor wetting of the rod or rods, will cause errors in indicated levels. The insulating bushing can be eliminated by converting the sensing rod to a resistive metal thimble with the connecting wire attached to the closed inner end of the thimble as shown in Figure 2. Using this approach, the electric circuit shows a relatively high resistance (thimble alone) and a low resistance when the sodium contacts the thimble.

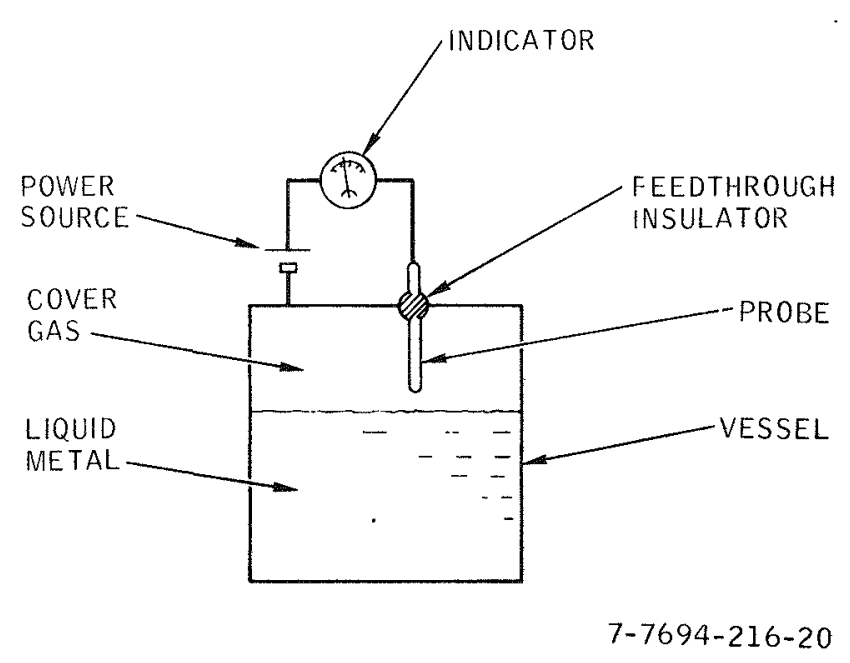

Figure 1. Insulated Contact Level Indicator

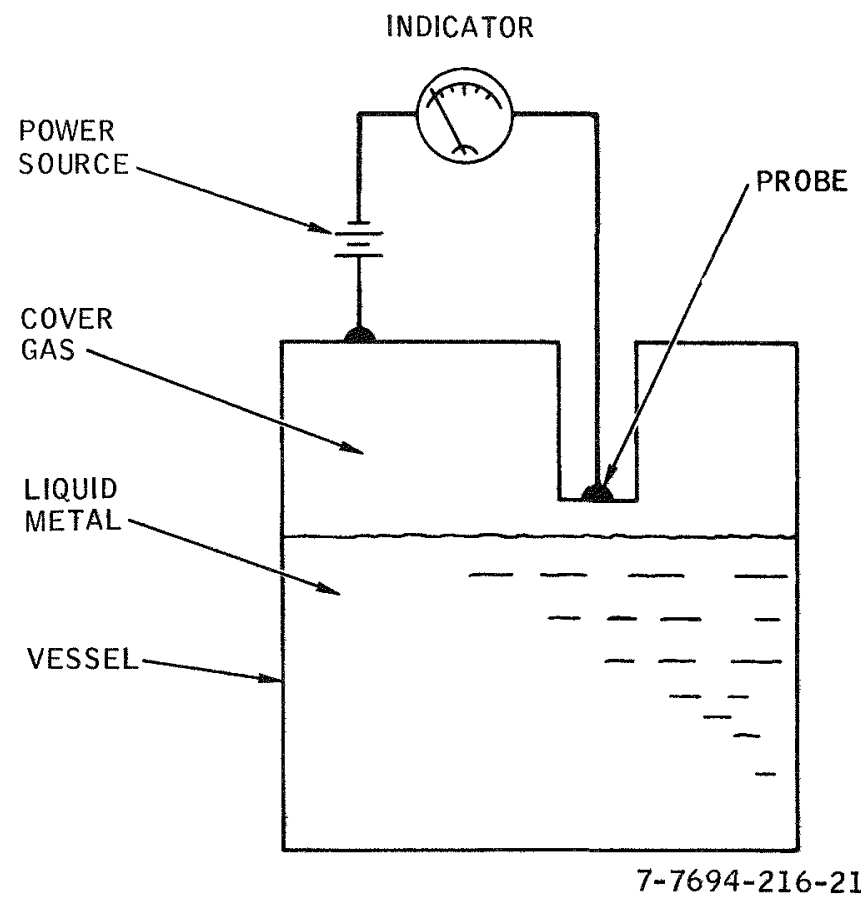

Figure 2. High Resistance Contact Level Indicator 


\section{RESISTANCE PROBES}

The resistance tube method, Figure 3, provides a continuous indication over a range of values. Its operation is based upon a measurement of the tube resistance along its length as the liquid metal surrounds and provides a much lower shunt resistance over the length covered.

The resistance tube has the best sensitivity and linearity when installed in the bottom of the liquid metal vessel, butfabrication problems and inaccessibility make it less desirable than an installation in the top of the vessel. The top mounting is illustrated in Figure 4. The vessel wall is then in parallel with the measuring circuit, reducing the sensitivity and producing non-linear voltage output.

To achieve the same desirable characteristics shown by the bottom-mounted resistance tube, the top-mounted tube is bent into a letter " $J$ " configuration and referred to as a $\mathrm{J}$ tube (Figure 5). The peculiar form of the $\mathrm{J}$ tube and the necessity for connecting the leads to the inner surface make this gage difficult to fabricate. Failures in early models occurred as the results of shorts between leads and walls and of leaks at the welded joints. Subsequent work by Pratt and Whitney Co. using swaged type material has produced easier-to-fabricate and more reliable $J$ tubes.

All resistance methods have the drawbacks of need for complete surface wetting, temperature sensitivity, and difficulty in repair or replacement (since this requires opening the vessel). 


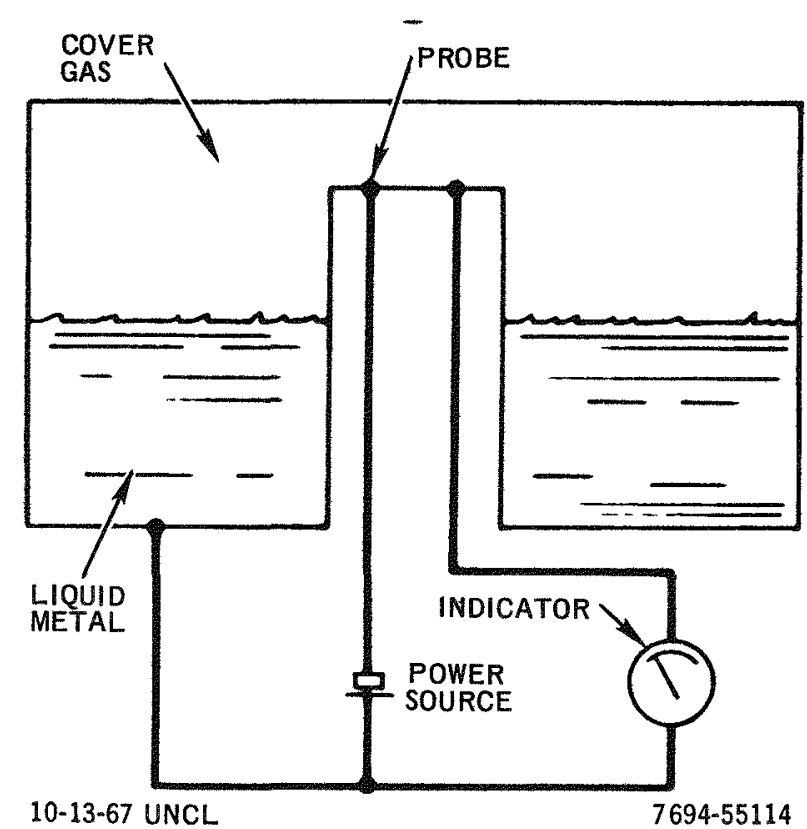

Figure 3. Resistance Tube Level Gage Mounted in Bottom of Vessel

1

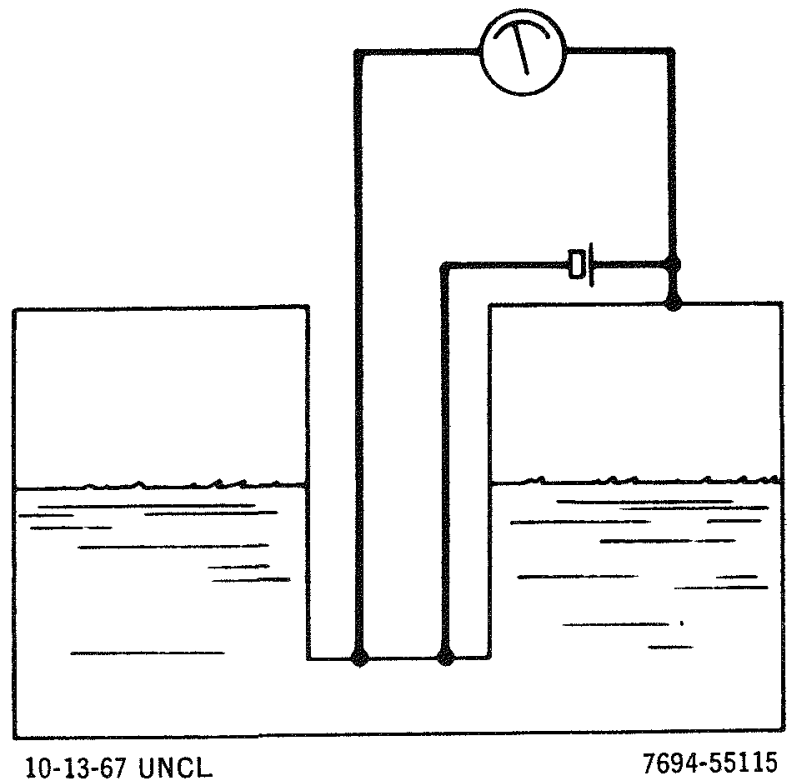

Figure 4. Resistance Tube Level Gage Mounted in Top of Vessel 


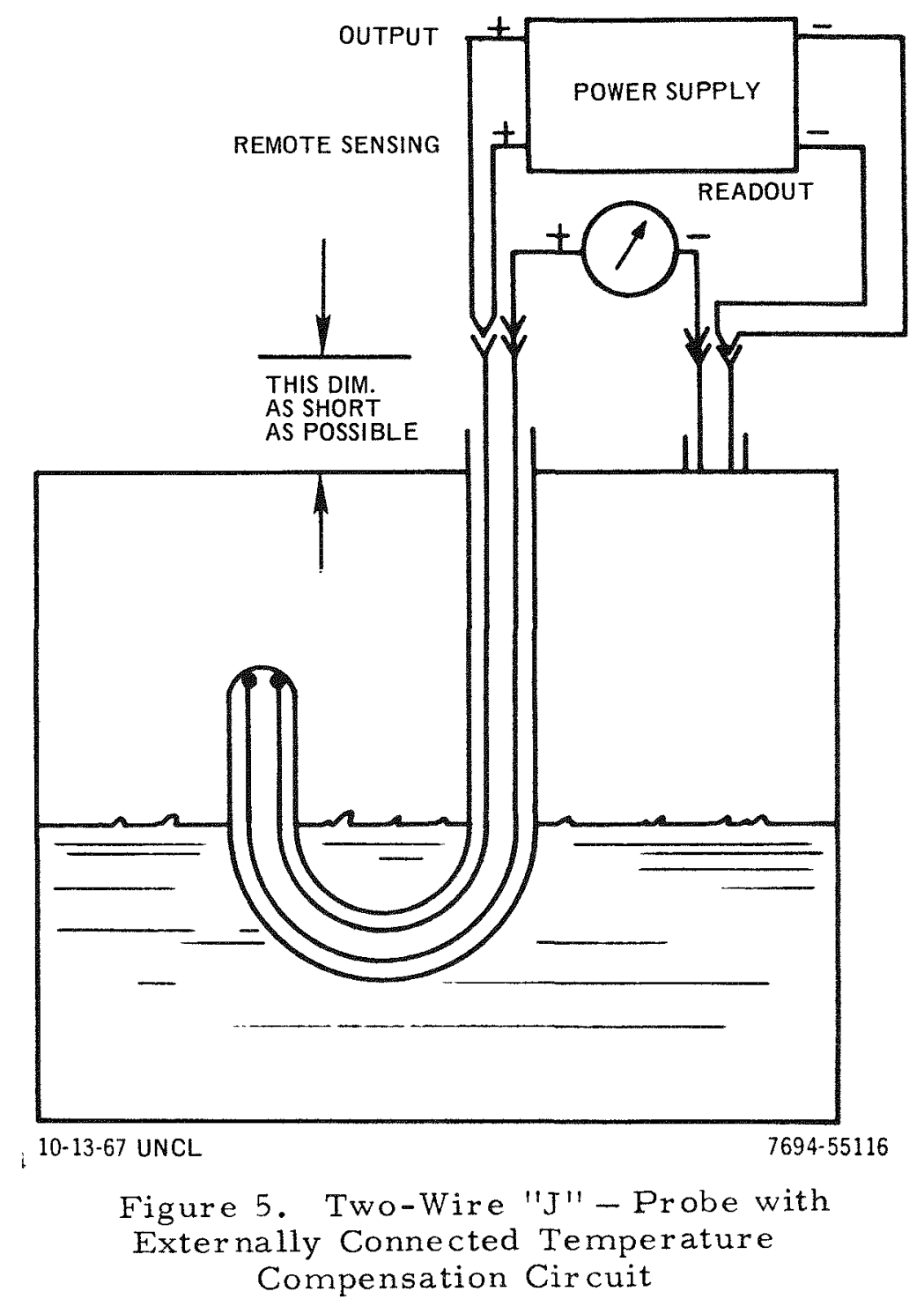

NAA-SR - MEMO- 12582 

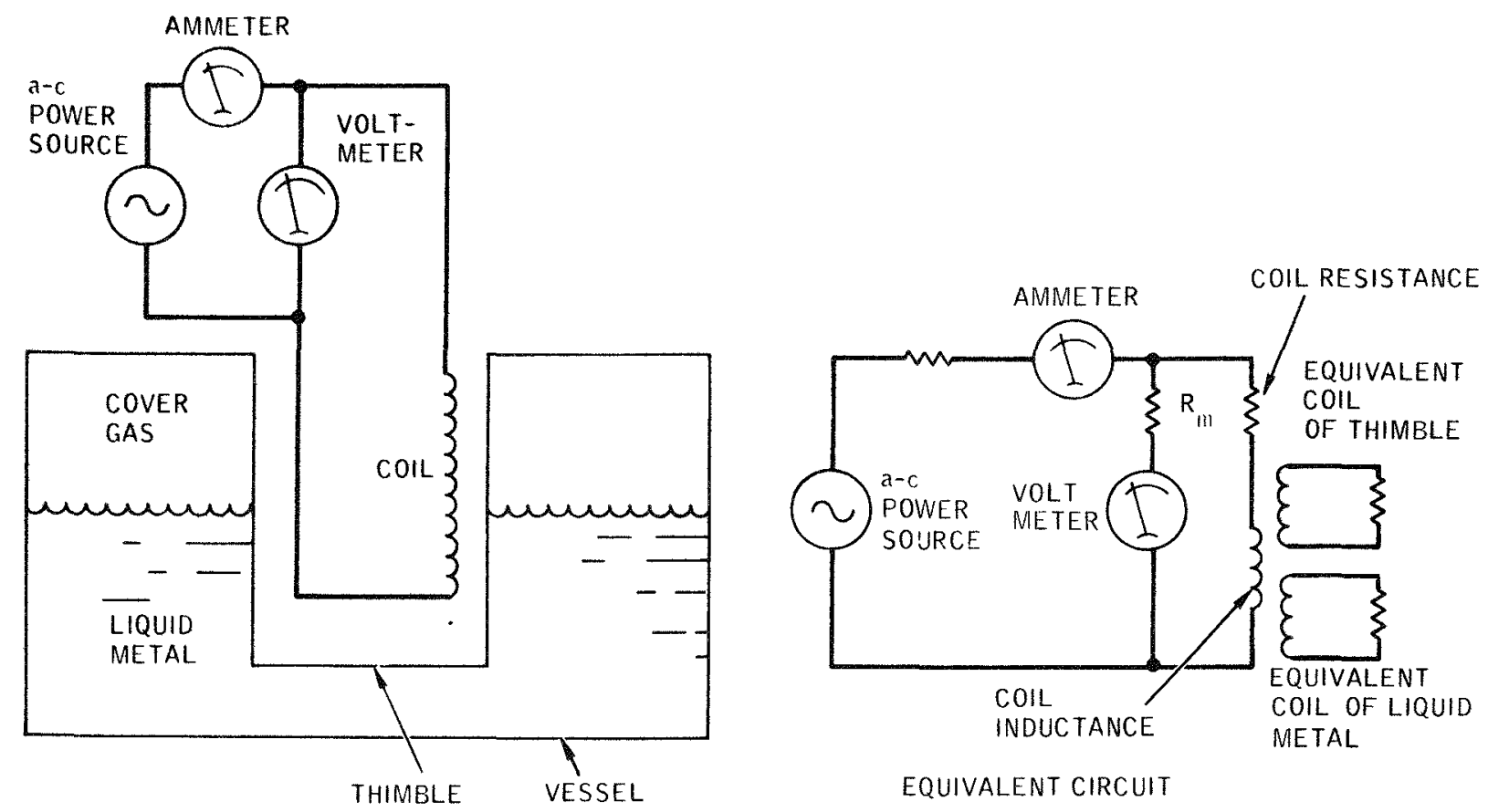

EQUIVALENT CIRCUIT

$7-7694-216-25$

Figure 6. Simple Induction Level Gage Design

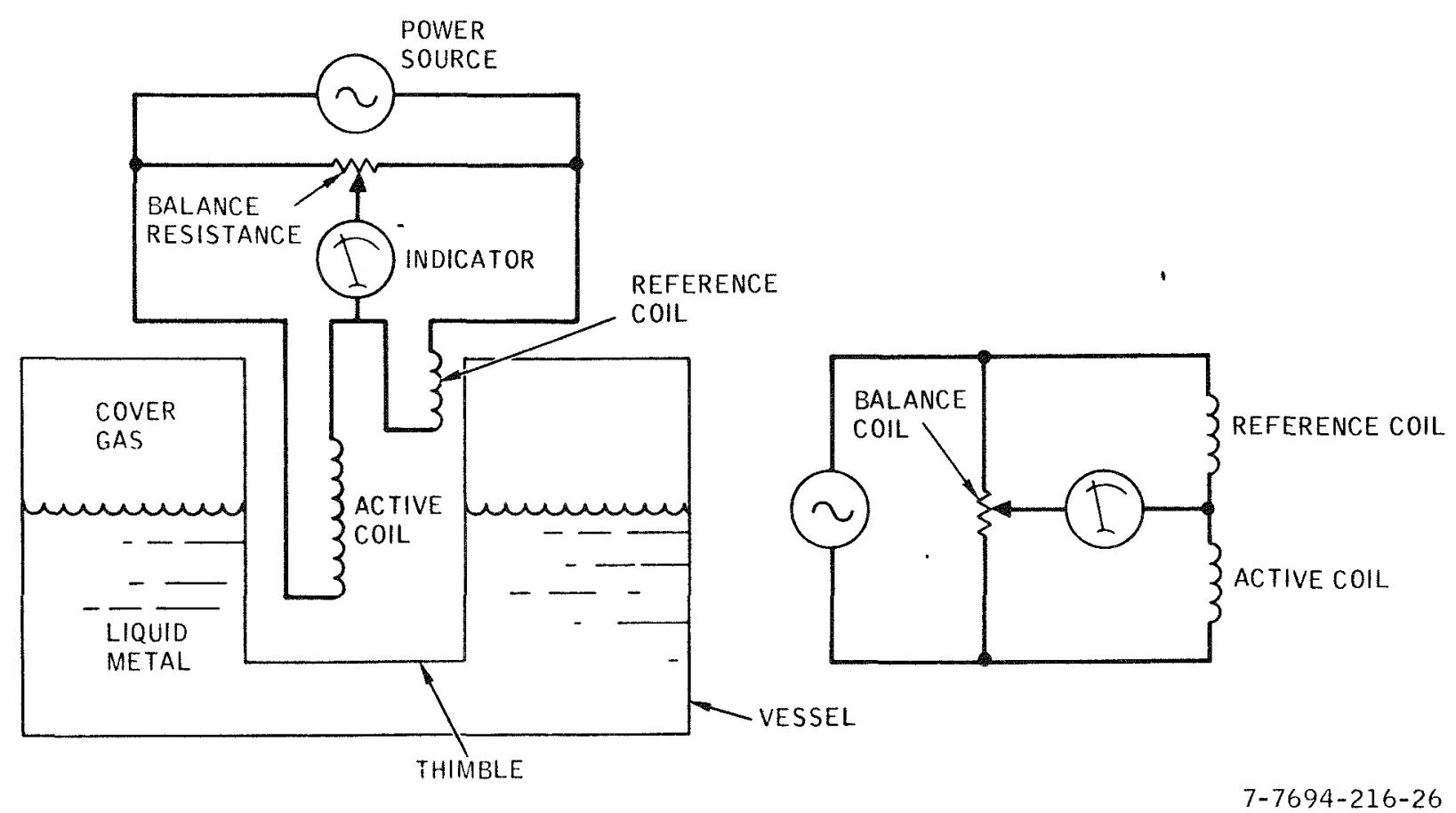

Figure 7. Inductance Level Gage Using a Temperature Compensating Circuit

$$
\text { NAA -SR - MEMO- } 12582
$$




\section{INDUCTIVE PROBES}

The problem of adequate wetting in the direct contact techniques previously described may be avoided by using the induction principle to establish the current in the liquid metal. The inductive techniques are therefore capable of providing a more reliable indication during initial operation of a system and in operation below $800^{\circ} \mathrm{F}$.

There are several types of inductive level measuring probes that have been used. All of them are inserted in a thimble built in the liquid metal containment vessel and are easily removed for repair or replacement.

\section{A. SINGLE COIL}

The simplest version of inductive probes is the single coil type illustrated in Figure 6. A coil energized by an alternating current induces a current in any closed conducting path surrounding the coil. The thimble and the liquid metal surrounding the thimble form conducting paths. The currents induced in the thimble result in a power consumption from the coil acting as the primary of a transformer. As the liquid metal rises along the thimble, additional power is consumed at a rate determined by the height of the liquid metal. An ammeter reading the current furnished to the coil can be calibrated in terms of liquid metal level in the vessel.

A disadvantage of this form of inductance probe is its temperature sensitivity. Since the current is a function of resistances and resistances are a function of temperature, the calibration is correct only at the temperature for which the calibration is made. If the primary coil is made with a low temperature coefficient wire and energized from a constant current supply, the temperature sensitivity due to changes in resistivity of the windings will be greatly reduced. The temperature sensitivity due to changes in resistivity of the sodium and thimble will remain.

\section{B. MULTICOIL, TEMPERATURE COMPENSATED}

An improved form of inductance probe uses a pair of coils in a bridge cir cuit, as shown in Figure 7. One coil (reference coil) is placed in the thimble out of the range of the liquid metal level and functions as a temperature compensating leg of the bridge. The active coil is placed within the liquid metal

$$
\text { NAA -SR - MEMO- } 12582
$$


level range of variability so that the impedance of the coil circuit varies as a function of the impedance in the secondary circuit, the thimble, and the liquid metal.

The resolution is proportional to the full scale reading (or coil length), so for applications involving a large range, the uncertainty in level indication may be excessive. To avoid this problem, it is customary to use the segmenting technique. In this method the coil length providing the resolution required is determined and a sufficient number of coils of this length are then stacked in the thimble to cover the required range. The coils are electrically connected to the bridge circuit through a selector switch. The level is determined by sequentially connecting the coils until the indicator shows which coil senses the liquid metal to gas interface. The position of this coil in the stack provides the reference value and the reading on the indicator provides the distance of the interface beyond the reference level. This method can be used as described for continuous liquid level measurement over a given range, or by the use of physically short coils located at selected levels to be used for alarm and/or control functions at the selected point.

The main disadvantage of this method is the number of leads to the coil assembly from the read-out equipment.

\section{COUPLED COILS}

A somewhat different approach uses the mutual inductance between two coils and the degree of coupling afforded by the liquid metal. The objective of this method is to reduce temperature sensitivity by arranging the circuit so that the coil resistance is not a factor. This is accomplished by operating the primary coil from a constant current power supply so that the magnitude of the current, and therefore the flux, is independent of the primary coil temperatureinduced resistance variations. Furthermore, by measuring the voltage induced in the secondary coilwith a high impedance voltmeter, effect of a variation in the resistance of the secondary coil is negligible.

There are several methods of using the variation of coupling. They differ in operating principle according to the manner in which the liquid metal affects the coupling.

NAA -SR - MEMO- 12582 
One method, illustrated in Figure 8, uses a bifilar winding on a core inserted into the thimble. In this method the coils are closely coupled initially, and the effect of the liquid metal surrounding them is to decrease the coupling. As the liquid metal rises around the thimble, the mutual inductance is progressively decreased with the consequent decrease in secondary voltage. The secondary voltage indicator is calibrated in terms of level.

Using the same principle but a different configuration, as shown in Figure 9, the coils are placed in separate thimbles. The coils are flat, that is they have a large equivalent diameter-to-length ratio, and are placed in the thimbles so that the coil axes are colinear and normal to the thimble axis. As the liquid metal rises around the thimbles, the coupling between the coils is reduced proportionally thus reducing the voltage output of the secondary coil. A number of factors contribute to the reduced coupling but the most evident is that contributed by the liquid metal functioning as a shield between the two thimbles.

An alternate design uses the mutual inductance effect in a different manner. This involves the coupling between two parallel adjacent coils mounted as a pair in a thimble as shown in Figure 10. Two such coils wound on non-magnetic cores have nearly zero electrical coupling when slightly separated and when no conductor encircles the pair. When the coils are surrounded by a closed circuit conductor, the coils are coupled. Such a pair, immersed in a thimble in a liquid metal system, shows a coupling as indicated by an output voltage increase as the liquid metal rises around the thimble.

In the last three methods described, the only factor contributing to the temperature sensitivity is the resistance change with temperature of the thimble and the liquid metal. The upper temperature limit is established by the coil materials. Coils used in evaluating the "parallel adjacent coil" method were wound of commercial stainless-steel-sheathed, magnesia-insulated, stainless steel wire. The performance was satisfactory, so it may be inferred that any of these methods may use such high temperature wire and be operated at temperatures approaching $2000^{\circ} \mathrm{F}$.

A three-coil probe, Figure 11, commonly made in the form of a "dipstick" is used to determine the location of the liquid metal-to-gas interface. When 

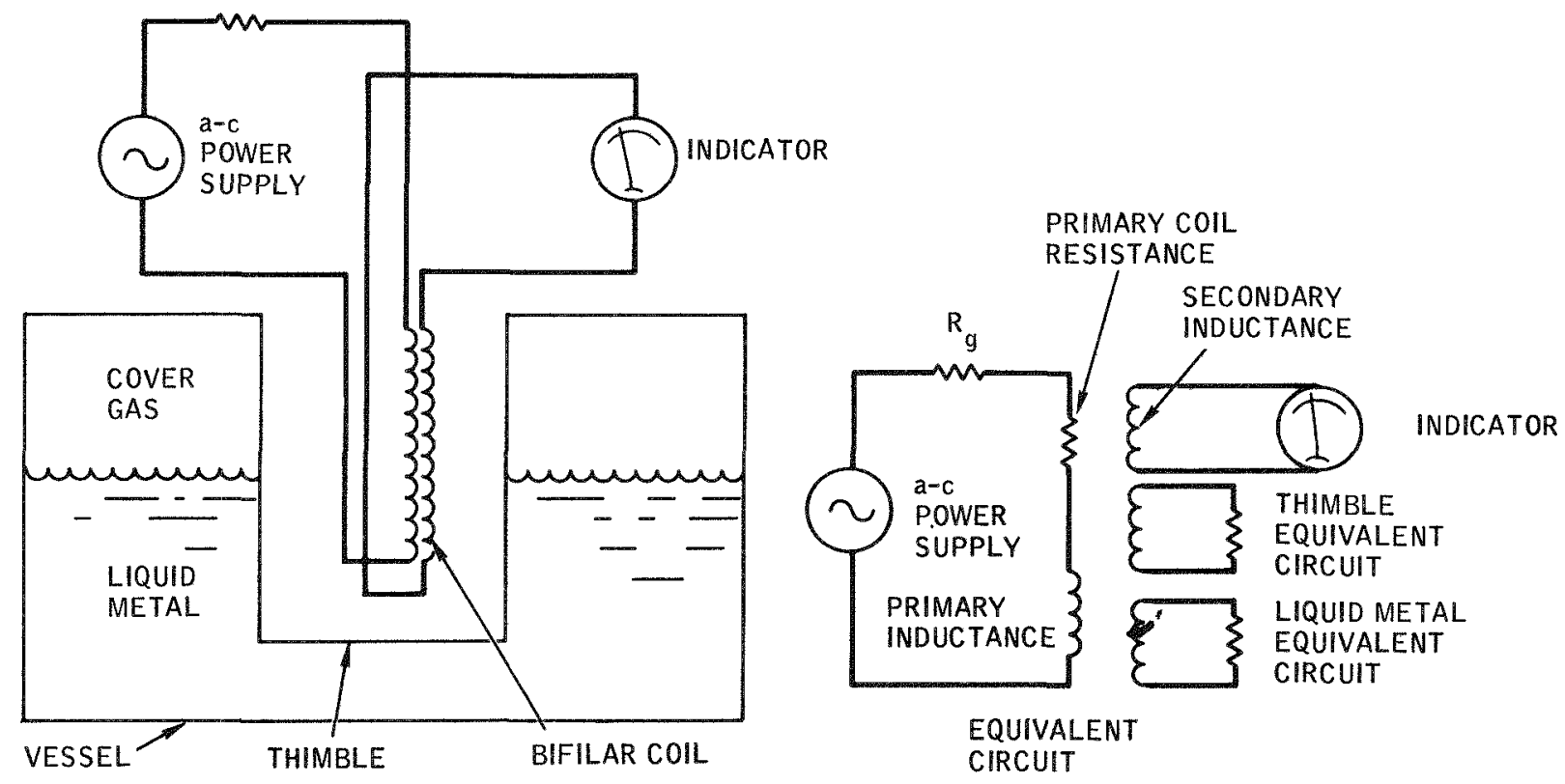

Figure 8. Level Gage Using Bifilar Coil
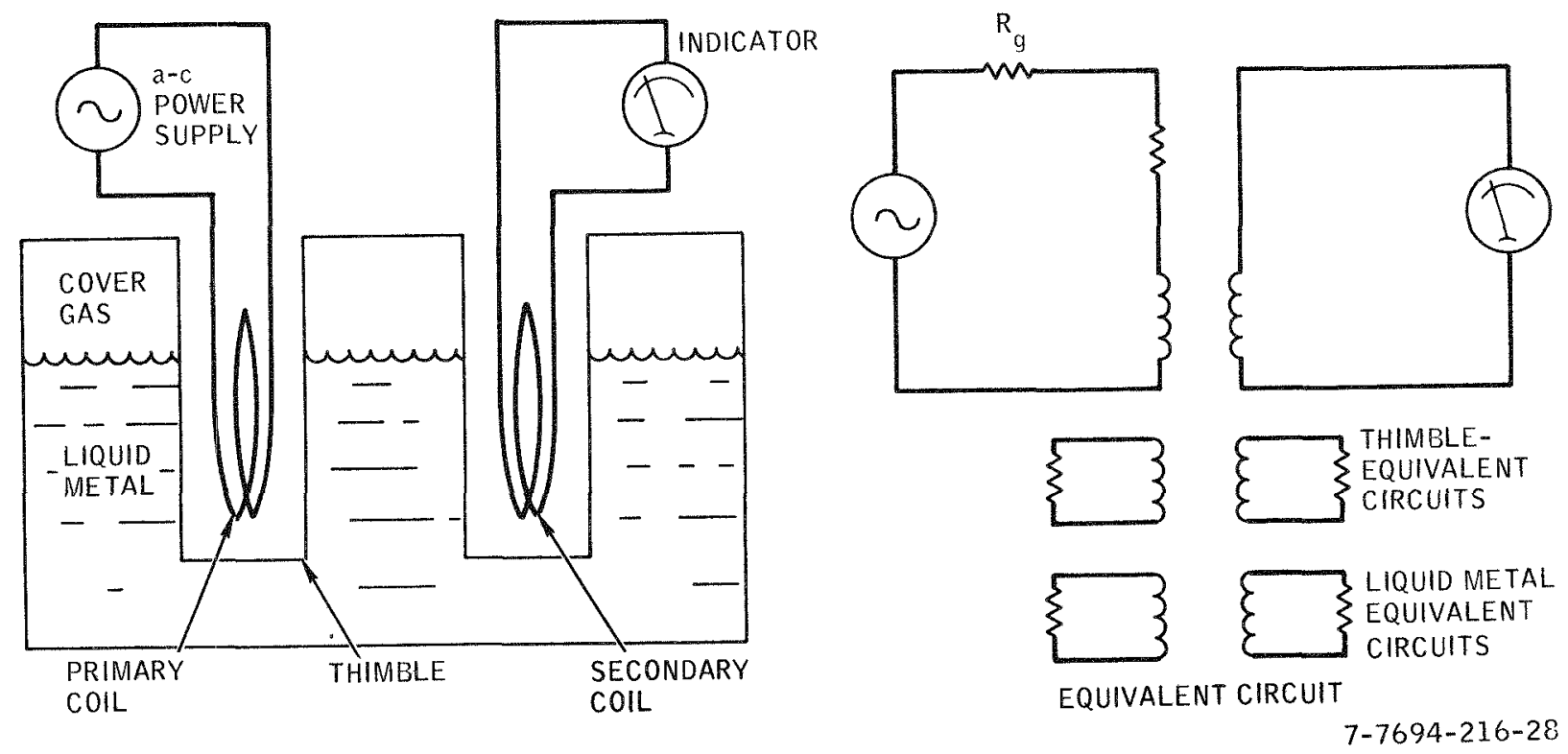

Figure 9. Level Gage Using Coils Inductively Coupled in Separate Thimbles 

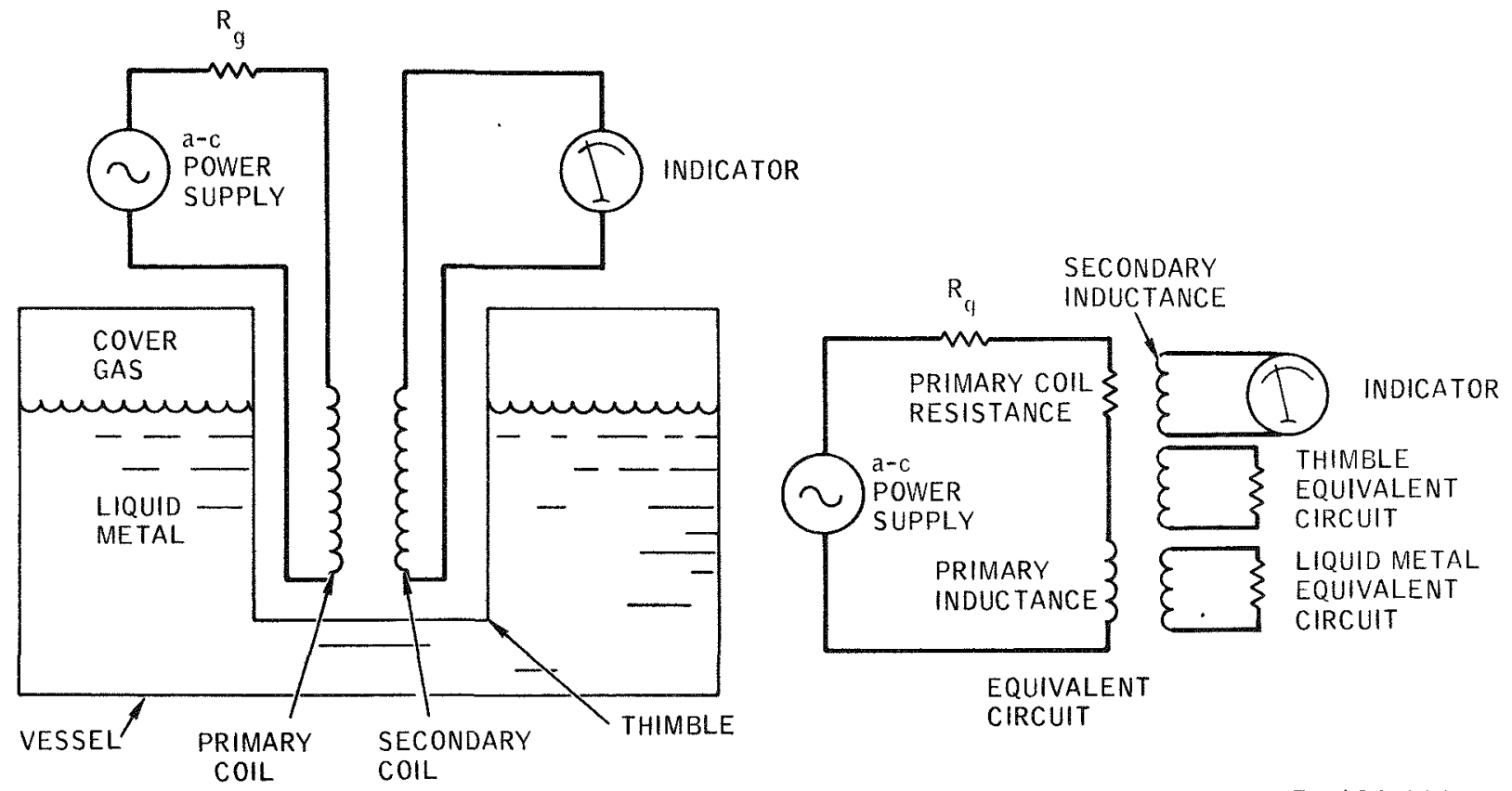

$7-7694-216-29$

Figure 10. Level Gage Using Coils Inductively Coupled by Liquid Metals

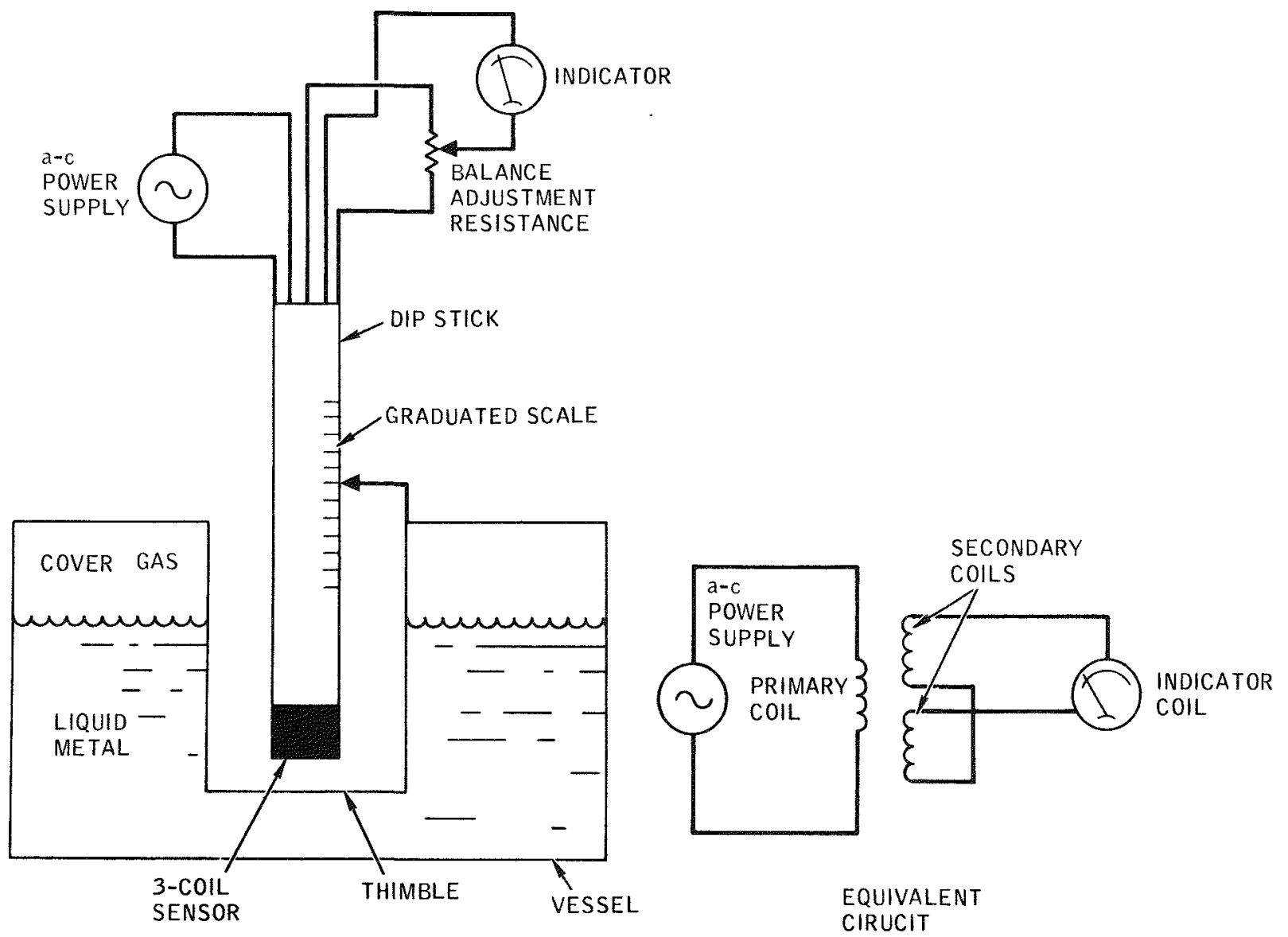

$7-7694-216-30$

Figure 11. Three-Coil Level Gage

NAA -SR - MEMO- 12582 
mounted in a fixed position, the probe is a single-point indicator. When it is mounted to move and follow the interface, it provides a continuous widc range indication.

The three coils comprise the primary and a split secondary coil. The centrally located primary coil is energized by an alternating current. The induced signal voltages in the upper and lower secondary coils are approximately equal. As the probe descends into the liquid metal, the lower coil will show a decrease in generated ac voltage due to the eddy current losses in the liquid metal. As the probe descends further, the upper coil will experience a similar change. The outputs from these coils are amplified. A biasing circuit causes the indicator to be at center zero when the liquid metal is at the center of the primary coil. Complete submersion will result in a minimum flux condition which is indicated as a full scale deflection of the indicator. Withdrawal of the probe creates a condition of maximum flux which results in full scale indication of opposite polarity.

This measuring device is primarily an interface detector in that it responds to different electrical conductivities between the liquid metal and the cover gas above the liquid metal. The instrument when properly adjusted can indicate whether the probe is above, at, or below the liquid metal interface, and can thus be used for alarm and/or control functions at a selected point.

This type of gage can also be operated by a servo-mechanism to provide a continuous indication over a wide range of values. 


\section{FLOAT TECHNIQUES}

As shown in Figure 12, there are two different types of float devices used for liquid level measurement: the surface type and the displacer type.

\section{A. SURFACE FLOAT}

The surface float uses a float attached to a pivoted arm. The arm actuates a position indicating device. The main drawbacks of this type of system are limited range of measurement and deposition of oxide or vapor on the moving parts.

\section{B. DISPIACER F LOAT}

The displacer type float uses a cylindrical displacer suspended from a leaf spring or torsion bar. A rise in liquid level about the displacer causes it to become effectively lighter by the weight of the liquid being displaced. A position sensor device on the spring arm or torsion bar gives a signal proportional to the displacer position or level. This type float measurement is usable for a range of up to $12 \mathrm{ft}$. The position sensor must be shielded against oxides or vapors and the displacer shielded against swirling currents in the vessel. This

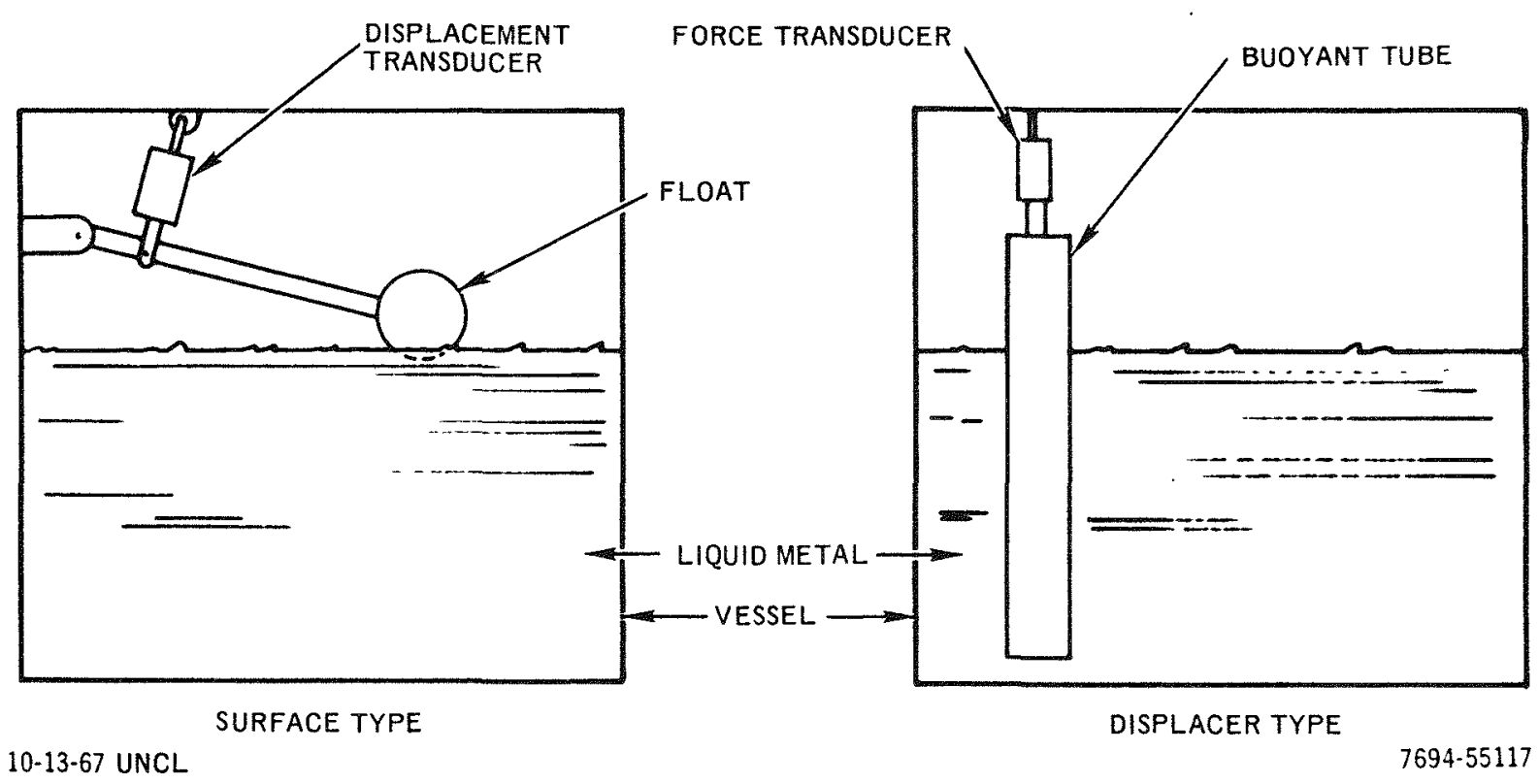

Figure 12. Float Type Level Indicators 
method is temperature sensitive due to the change in density of the liquid metal with regard to temperature.

It has been suggested that this method of level measurement could be remotely tested for response by using a solenoid to put a known twist on the torsion bar. When the solenoid is energized by a remote push button, the level indicator should show a definite response. 


\section{PRESSURE TRANSDUCERS}

Liquid metal levels have been measured by using differential pressures. A typical arrangement is shown in Figure 13. The pressure at the bottom of the measured range, less the cover gas pressure, is a measurement of hydrostatic head of the liquid metal above the lower pressure gage.

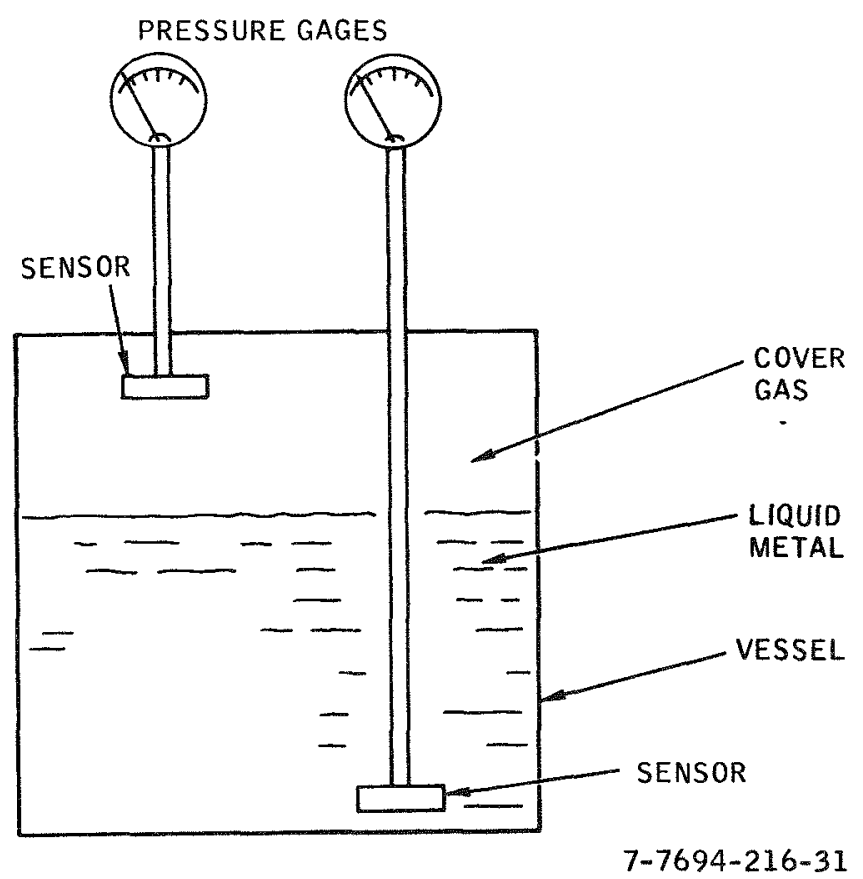

Figure 13. Differential Pressure Method of Measuring Level

Another method similar in principle is the bubbler technique. This involves immersing a tube connected to a gas supply with a pressure gage into the liquid metal and allowing gas to escape from the end of the tube and bubble to the surface. To produce bubbling, the difference between the cover gas pressure and the gas pressure is the liquid pressure at the submerged end of the tube. The height is equal to the differential pressure divided by the liquid metal density at that temperature.

The differential pressure and bubbler techniques are dependent on the density of the liquid metal, and the density varies with temperature. Temperature correction charts or temperature compensation in the indicator is required.

NAA -SR -MEMO- 12582 


\section{OTHER DEVICES AND TECHNIQUES}

\section{A. THERMAL CONTACT PROBES}

The the rmocouple liquid level technique is dependent upon the liquid metal temperature being significantly different than the cover gas temperature. The method consists of inserting thermocouples into the vessel at various heights. When the thermocouple is not in contact with the liquid metal, it will indicate a temperature approximately that of the cover gas. Contact with the liquid metal changes the temperature indication to that of the liquid metal. To provide a range of values, an array of several thermocouples is used.

One application developed for Dounreay Reactor uses a reference thermocouple in the sodium, several thermocouples in a vertical configuration in the vessel, and a rapidly commutating solid state switch. The switch constantly switches the thermocouples in sequence to a comparator circuit with the reference thermocouple. All thermocouples above the liquid metal will have at least a $120^{\circ} \mathrm{F}$ lower temperature than the reference thermocouple. The comparator output operates light bulbs to give a visual indication of liquid level and operate alarms. This method can be adapted to operate a recorder.

Another design uses eight thermocouples attached at 1 -in. intervals along the length of a metal sleeve inserted in an aircooled thimble which in turn is immersed in the liquid metal.

\section{B. ELECTRICAL CAPACITANCE PROBES}

Liquid metal level may be measured by the change of electrical capacitance as the liquid metal rises around a dielectric coated metal rod immersed in the liquid metal (Figure 14). The capacitance is measured by a capacitance bridge and translated into an equivalent level. Recent work on alumina to metal seals indicates that suitable high temperature probes can be made.

\section{GAMMA RAY ABSORPTION TECHNIQUE}

Liquid metal level measurements using gamma ray absorption techniques have been used. The operation is based on the fact that gamma rays will penetrate the vessel and liquid metal, but the intensity will be attenuated in passage. 


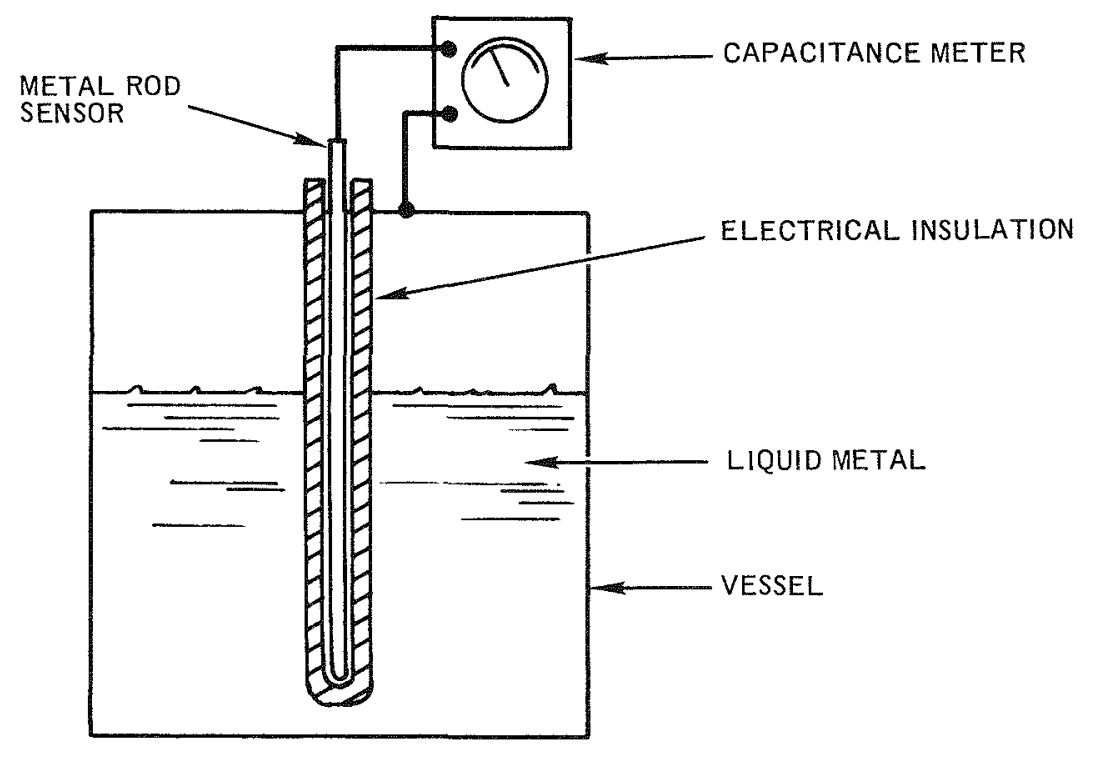

10-13-67 UNCL

$7694-55118$

Figure 14. Electrical Capacitance Level Gage

In one design, shown in Figure 15, the gamma source and sensor are mounted on a common support arranged so that the radiation traverses the vessel. The support level or height is controlled by a mechanism which is controlled by the sensor. When the support is above the liquid-to cover gas interface, the attenuation is less than when it is below the level, since the absorption in the liquid metal is greater than that of the cover gas. A servosystem deriving a control signal from the sensor and driving the elevating mechanism maintains the sensor height at the interface level. This provides a continuous level indication either by direct measure or by a signal derived from the servo-circuit.

Another method uses a fixed gamma source and a long detector. As the liquid metal rises in the vessel an increasingly longer portion of the detector is shadowed. The detector signal output is translated into an equivalent level measurement. This method is temperature sensitive due to differences in liquid metal density at different temperatures.

For single-point level measurement the method is simplified by using a fixed mounting of the source and sensor and the signal indicates simply that the level is above or below the point. Except for difference in thermal expansion 


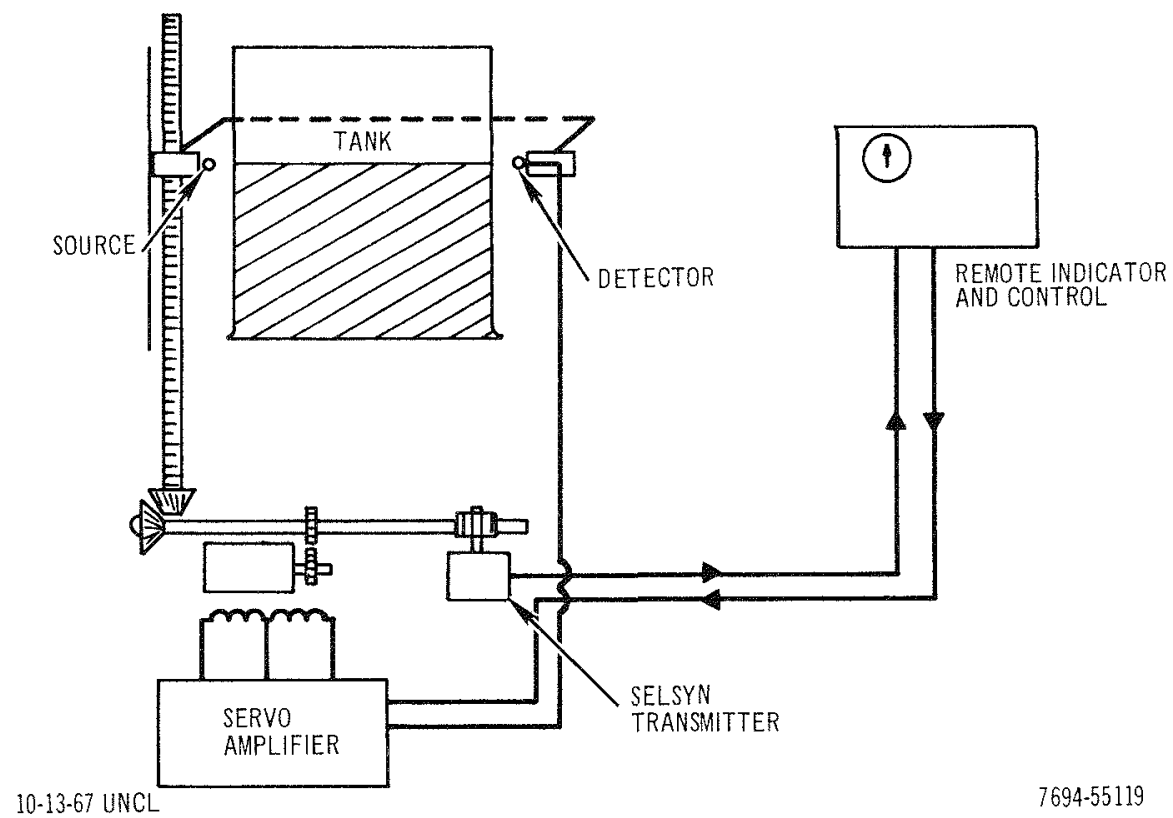

Figure 15. Gamma Ray Level Indicator

between supports and vessel this method is not temperature sensitive. The sensor may be mounted far enough from the vessel that it may be kept cool enough for satisfactory operation.

While the gamma attenuation method circumvents many of the problems found in other methods, it has some limitations, namely, interference from other radiation sources when used in a high radiation environment and the introduction of radiation in an otherwise radiation-free region.

\section{RESONANT UHF LINE PROBE}

A proposed method of liquid level measurement uses the variation in the inductance of a metal rod dipped into the liquid metal. If the liquid is assumed to be a perfect conductor, the inductance measured is of that portion of the rod not covered by the liquid metal. Inductance is measured by the resonance method.

When the liquid to be measured is contained in a metal tank, the tank wall may be regarded as a tube, but the calibration of the instrument would depend on the size and shape of the tank. In general, it is more convenient to have a self-contained probe unit consisting of a rod and a perforated tube forming a rigidco-axial line, as shown in Figure 16. If the line is of uniform cross-section, a linear relationship exists between its inductance and the liquid level.

$$
\text { NAA -SR - MEMO- } 12582
$$




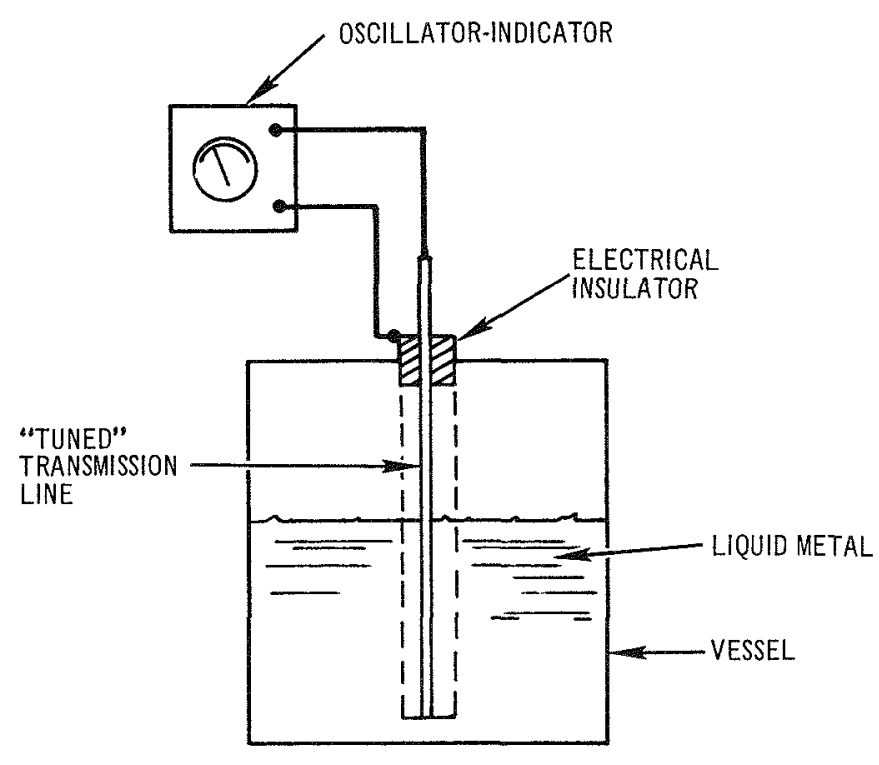

10-13-67 UNCL

$7694-55120$

Figure 16. Resonant Transmission Line, Level Gage

\section{E. SONIC ECHO RANGING}

Figure 17 illustrates the sonic, or echo ranging, technique of liquid level measurement which uses a transducer to generate a sound pulse directed toward the liquid metal surface. The reflected pulse from the surface is detected by the same, or an adjacent, transducer. The time interval between the transmitted and reflected pulses is a measure of the distance between the liquid metal level and the transducer.

An ultrasonic, single point, level probe has been used to detect the level of salt, and it is suitable for use in liquid metal systems. The instrument is basically an acoustic impedance device and consists of an electronic power oscillator, a magnetostrictive transducer, a standing wave ratio detector, a transmission rod, one or more force-insensitive feedthroughs, and a sensing plate. This device is illustrated in Figure 18. Energy is supplied to the transmission rod through the magnetostrictive transducer at a frequency that causes the rod to resonate. The force-insensitive feedthroughs allow the excitation rod to penetrate containment vessels without prohibitive loss of ultrasonic energy and without compromising containment. 


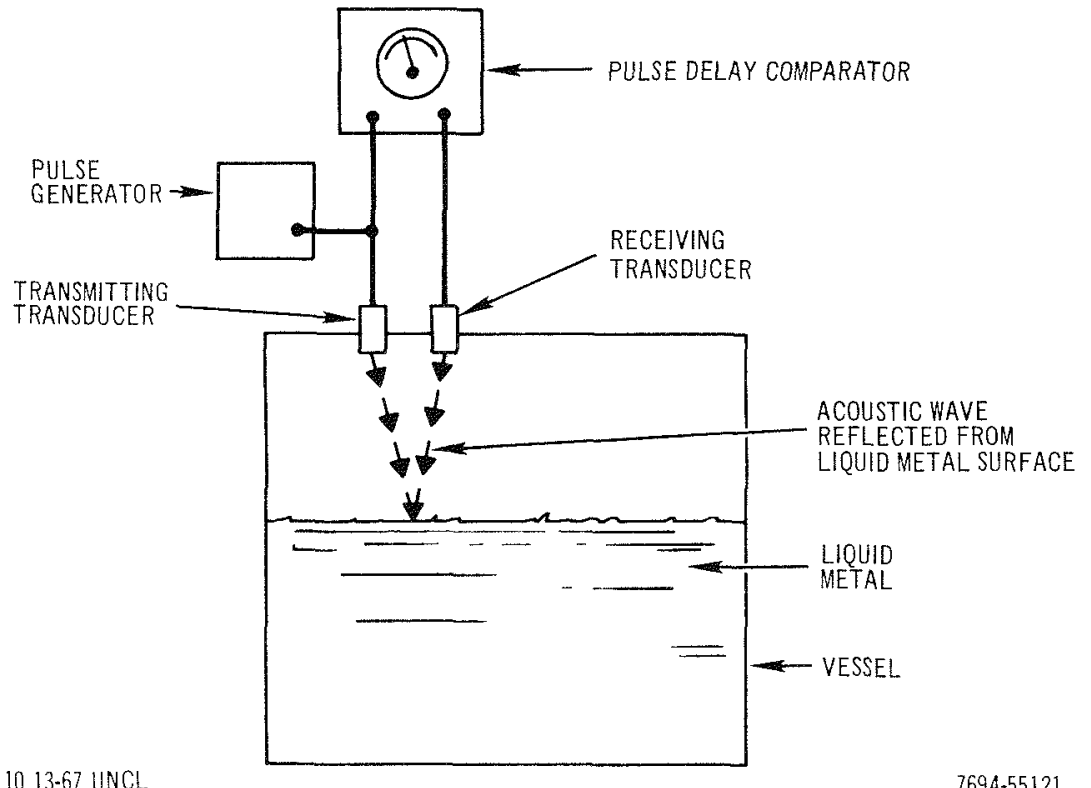

Figure 17. Echo Ranging Method of Level Measurement

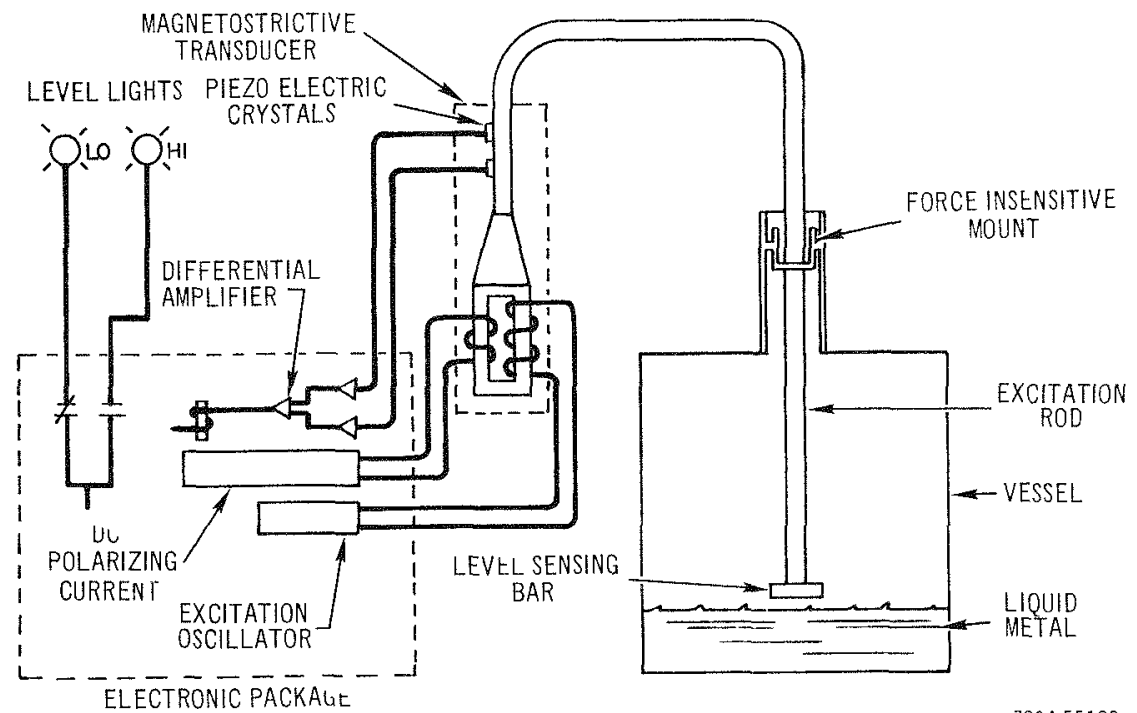
101367 UNCL

769455122

Figure 18. Ultrasonic Level Gage, Standing Wave Ratio Type 
The presence or absence of fluid is determined by detecting the decrease in the standing wave ratio present on the resonant transmission rod.

\section{F. TIME DOMAIN REF LECTOMETRY}

Time domain reflectometry has become so useful in identifying discontinuities in radio frequency transmission lines that at least two oscilloscope manufacturers now offer instruments designed specifically for this method of measurement. Theidea of this technique is simple: a long, very fast rising pulse is fed to a transmission line. The physical arrangement is similar to that shown in Figure 16. When the wave encounters an impedance mismatch along the line, a portion will be reflected back toward the sending end. If an oscilloscope is used to view the sending-end conditions, the source of each reflection can be located from the time of its return.

A transmission line entering a liquid will show a discontinuity at the liquid surface, and the methods of time domain reflectometry can be used to measure the liquid level. As an added feature of this technique, discrete insulators or metal washers can be added to the line to create impedance mismatches at known points. These produce internal reference marks on the oscilloscope display that make the system calibration-free. Since the device uses no complicated transducer mounted at the vessel, it can be used in very severe temperature and radiation environments.

An oscilloscope readout is satisfactory for those familiar with oscilloscope operation but, to those unfamiliar, readout can be difficult to interpret. One of the manufacturers has developed a converter circuit to transform the time indication to a millivolt signal for the TDR oscilloscope. It provides a fairly high, adjustable, dc output with a zero suppression for use with most recorders.

\section{G. SIGHT TUBE}

A proposed method of liquid metal level measurement utilizes a metal "sight tube" attached to the side of the containment vessel as illustrated in Figure 19. A large alternating current is induced into the sight tube as a shorted turn secondary of a transformer. A metal $U$-shaped reference arm on the sight tube, the legs of which are spaced the length of the measured range, forms two legs of a bridge circuit. The sight tube itself forms the other two legs of

NAA-SR - MEMO- 12582 


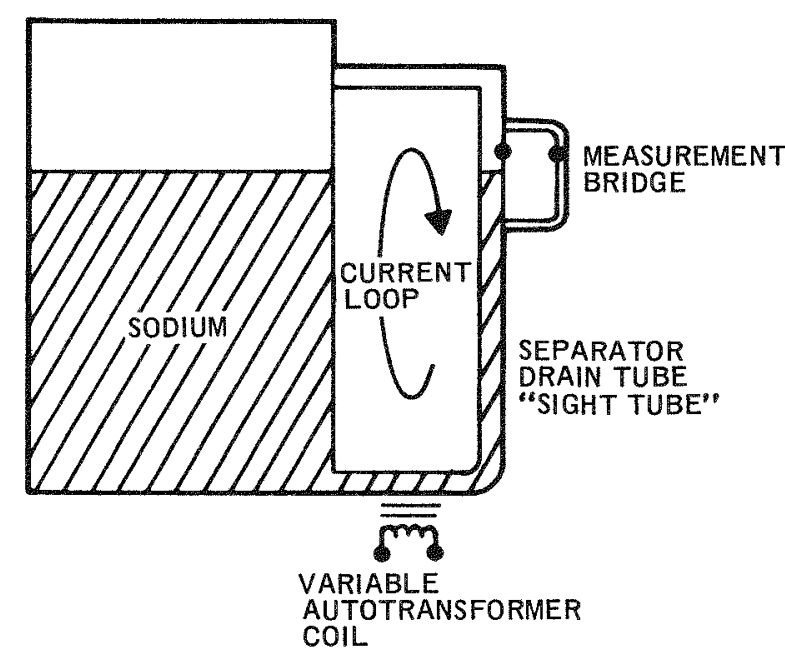

10-13-67 UNCL

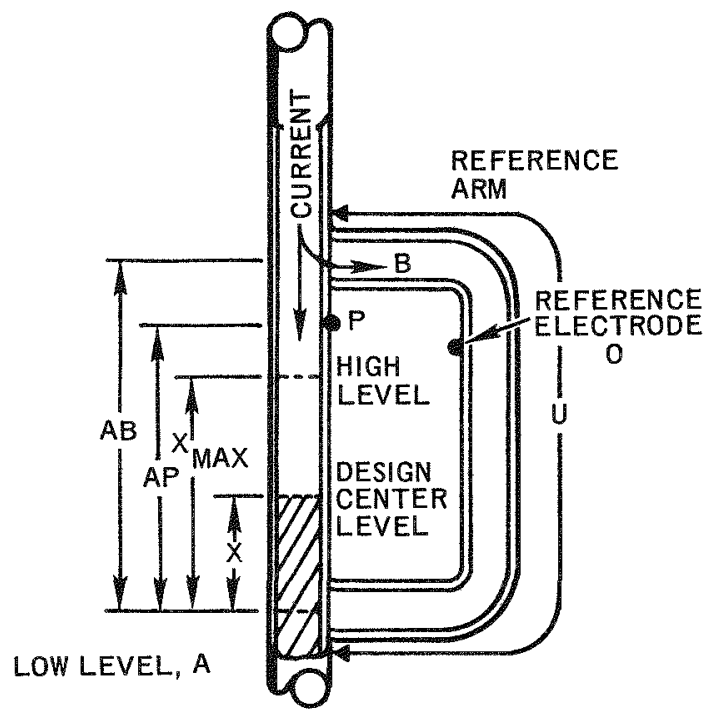

DETAIL OF MEASUREMENT BRIDGE

Figure 19. "Sight Tube" Level Gage

the bridge circuit. As the liquid metal rises in the sight tube, we bridge becomes progressively unbalanced, giving a measurement of the height of the liquid metal.

\section{H. WEIGH TANK}

The weight tank method has been used in other process applications and can be used for liquid metals. This method consists of weighing the vessel and computing the level from the vessel dimensions and liquid density. This method has the advantage that all measurements are external to the vessel, but it is an awkward method and not in general usage. In liquid metal applications, awkwardness arises from the peculiar vessel support requirements and the necessary flexible piping connections. 


\section{EVALUATION}

The most commonly used methods of liquid metal level measurement to date have been the resistance and inductive type probes and the pressure transducers.

The resistance probes have been well developed and no additional development work is needed for their use in liquid metal systems.

The inductive type probes have been developed for somewhat lower temperatures. Newer materials are now available and small development work would be required to develop probes that would be reliable up to $1500^{\circ} \mathrm{F}$ and in a high radiation environment.

The pressure transducers used to date have not been an unqualified success. They have required frequent calibration and, in some cases, have been plagued by oxide build-up on the bellows or diaphragms. Furthermore they are bulky and their air lines or capillary tubes make repair or replacement difficult, if not impossible. Extensive development work on smaller, preferably electrical rather than pneumatic, transducers is needed if this technique of level measure- . ment is desired.

The choice of a suitable liquid metal level measuring system must take into account several factors listed below.

1) Range to be measured

2) Continuous or point indication

3) Accuracy needed

4) Environment: temperature, pressure, etc.

5) Service life expectancy

6) Accessibility for maintenance.

The inductance method of level measurement has the best combination of advantages vs disadvantages at the present time. The outstanding advantage is that the detectors are inserted in thimbles installed in the containment vessel. There is no contact with the liquid metal, and maintenance is relatively easy. 
For general liquid metal level measurement or control over shorter ranges, the bifilar coil is recommended. It is easy to construct, requires the least amount of connecting leads, and requires the least complicated electronic circuitry.

For general level measurements or control over longer ranges, the multicoil arrangement in a bridge circuit is recommended. The indicator can be fully automatic and continuous by using optical meter relays, a stepping switch, and a voltage divider. The major disadvantage is the larger number of interconnecting leads to the probe.

The tri-coil level probe is the most accurate of any method used. It has an accuracy of $\pm 1 / 16$-in. and can be used in a fixed position, manually positioned for calibration purposes, or can be automatically positioned by a servomechanism. The necessary servo-motor circuitry is relatively simple and is available from several manufacturers.

If the tri-coil is used with a servo-mechanism, simple system operating tests can be made at any time. A manual override switch is used to shift the probe from the indicated position. When the switch is released the probe should return to the same indicated position.

The displacer float method is being used successfully at the Sodium Components Test Installation (SCTI). It is bulky and would be hard to service. However, by proper shielding of the torsion bar transducer, and a device such as a solenoid to apply known loads to the torsion bar for system operational tests, this method of level measurement could be considered for some applications that involve measurements less than $\sim 10$ to $12 \mathrm{ft}$.

Two proposed techniques that show the best promise for future development work are the sonic echo ranging and Time Domain Reflectometry (TDR). Unfortunately both these techniques require location of the sensor within the containment vessel.

The sonic echo technique offers the advantages of high accuracy, slight temperature effects, and the ability to measure the distance to the liquid metal surface regardless of surface oxides or other contaminants. The transducers require development to operate at $1200^{\circ} \mathrm{F}$. The readout equipment is an off-theshelf item and available from many sources. 
The TDR technique is inherently self-calibrating at all times during operation. It has been used in molten glass, boiling water, and liquid hydrogen. Readout equipment is available from at least two manufacturers. The probe does not require wetting by the liquid metal and, due to the coaxial structure, is mechanically simple and rugged.

All of the described methods of liquid metal level measurement are summarized in Table 1. A comparison of previous usage, temperature ranges, accuracies, etc., may be made of the many level measuring techniques possible from these charts. 
$$
\text { . }
$$ 


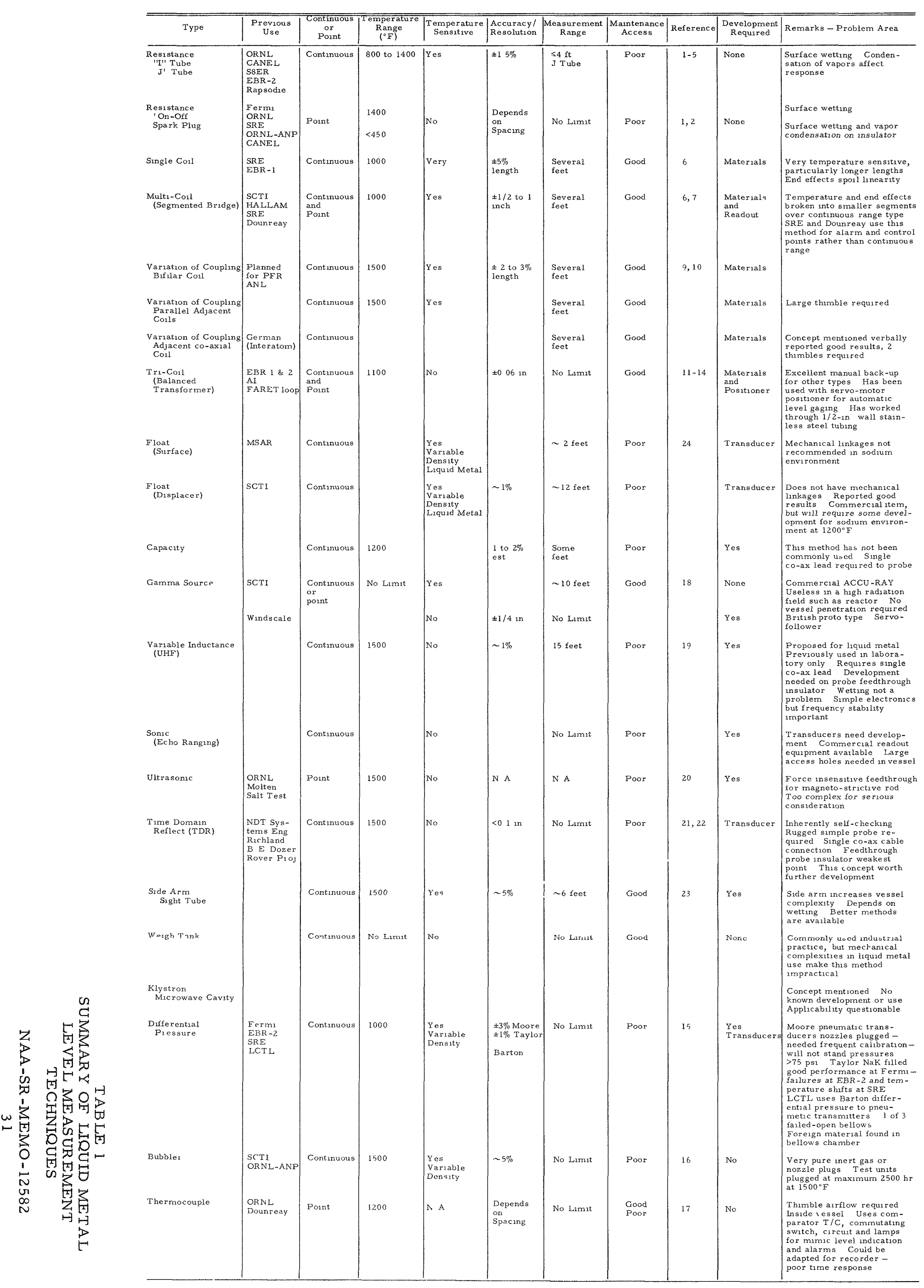


$$
\text { . }
$$ 


\section{REFERENCES}

1. R. G. Affel, G. H. Burger, and R. E. Pidgeon, "Level Transducers for Liquid Metals," ORNL 2792 (April 28, 1960)

2. S. J. Fanciullo, "Development of Liquid Metal Level Probes," PWAC 423 (April 27, 1964)

3. C. R. Droms, "Second Report on Liquid Metal Level Instruments," (December 21, 1954)

4. N Lions, "Instrumentation in the 1 and 10 Mev Test Loops at RAPSODIE," AEC-TR-6382 (1963)

5. M. W. Hulin and J. Beall, "Preliminary Results of the SNAP 2 Experimental Reactor," NAA-SR-5991 (April 1961)

6. G. E. Turner, "A Coil Type Level Gage for High Temperature Liquid Metals," NAA -SR -4195

7. S. Siegal and R. W. Dickinson, "The Modified Sodium Reactor Experiment. Power Reactor Experiments, Vol II," NSA-15-7551 (1962)

8. P. B. F. Evans, et al, "Control and Instrumentation of a Prototype Fast Reactor," CONF-BNES-66-5A/5 (May 1966)

9. G. Bottomley, "A Liquid Metal Level Indicator," NSA-9-4231 (March 1955)

10. T. R. Johnson, et al, "An Induction Probe for Measuring Liquid Levels in Liquid Metals," ANL-7153 (February 1966)

11. Instrumentation and Controls Conference, Gatlinberg, Tennessee, ORNL-2695 (April 22, 1960)

12. A. G. Hasler and F. A. Smith, "Conference on Application of High Temperature Instrumentation to Liquid Metal Experiments," ANL-7100 (September 29, 1965)

13. R. A. Clark, "Operational Experience and Developmental Activities in LASL Sodium Systems," SAN-8002, p 286 (May 1964)

14. R. V. Inman, "Theory of Operation and Characteristics of Transistorized Level Box Readouts," AI-TDR-4144 (May 1967)

15. G. H. Reicks, "Sodium Level Detectors in the Enrico Fermi Atomic Power Plant," APDA-3000 (November 30, 1965)

16. W. H. Jordan, et al, "Aircraft Nuclear Propulsion Project Quarterly Progress Report, Period Ending September 10, 1956," ORNL-2 157 (December 13, 1956)

$$
\text { NAA -SR - MEMO- } 12582
$$


17. R. D. Peak, "Thermocouple Liquid Level Indicator Used on Cold Trap Stands," CF-58-10-13 (May 1955)

18. A. P. Dixon, "A Liquid Metal Level Indicator Employing Gamma Radiation Techniques," R and DB/W/TN-206 (May 1955)

19. D. F. Davidson and J. Pilling, "A High Frequency Inductance Level Guage for Liquids in Inaccessible Locations," IGR-R/CA (1957)

20. H. J. Metz and M. N. Yurosh, "Experiences and Developments for Liquid Metal Experiments. Fourth High-Temper ature Liquid-Metal Heat Transfer Technology Conference," ORNL-P-1661, Conf-650946-2 (September 1965)

21. B. E. Dozer, "Liquid Level Measurement for Hostile Environment," Instrumentation Technology (February 1967)

22. "Time Domain Reflectometry," Hewlett-Packard Application Note No. 2 (1962)

23. J. Hyman, Jr. "Low Impedance Bridge for the Measurement of Level of Liquid Metals," RSIN-32-833-61 (1961)

24. V. K. Heckel and E. C. King, "Performance of a Frozen Seal on a 120 GPM Duriron Centrifugal Pump," MSA-Memo Report-61 (June 28, 1954) 